\title{
Criopreservação e desenvolvimento in vitro de embriões bovinos.
}

\author{
Alessandra Corallo \\ $\mathrm{NICACIO}^{1}$ \\ Mayra Elena Ortiz D'Ávila \\ ASSUMPÇÃO ${ }^{1}$ \\ Heloísa Vasconcellos do \\ Amaral CAETANO ${ }^{1}$ \\ Renato Pereira da Costa \\ GERGER ${ }^{1}$ \\ Mariana Groke MARQUES ${ }^{1}$ \\ Marco Roberto Bourg \\ MELLO ${ }^{1}$ \\ Camilla Mota MENDES \\ Marcella Pecora \\ MILAZZOTTO ${ }^{1}$ \\ Viviane Purri OLIVEIRA ${ }^{1}$ \\ Renata SIMÕES ${ }^{1}$ \\ Claudia YAMADA ${ }^{1}$ \\ José Antônio VISINTIN ${ }^{1}$
}

Correspondência para:

ALESSANDRA CORALLO NICACIO

Departamento de Reprodução Animal Faculdade de Medicina Veterinária e Zootecnia

Universidade de São Paulo

Av: Prof. Dr. Orlando Marques Paiva, 87 CEP: 05508-000

alezinh@yahoo.com

Recebido para publicação: 12/02/2004 Aprovado para publicação:01/06/2005

1 - Departamento de Reprodução Animal da Faculdade de Medicina

Veterinária e Zootecnia da Universidade de São Paulo, São Paulo - SP

\section{Resumo}

Palavras-chave:

Embrião.

Bovinos.

O objetivo deste trabalho foi estudar a remoção do crioprotetor, em duas ou três etapas, em embriões bovinos produzidos in vitro após a congelação em vapor de Nirtogênio. Blastocistos expandidos (1329) foram mantidos em co-cultivo (controle) ou criopreservados em 3 protocolos de congelação em vapor de nitrogênio. Os embriões foram equilibrados na solução de $10 \%$ de EG por 10 minutos e em $17 \%$, $22 \%$ ou $28 \%$ de EG por 30 segundos. Após o envase, as palhetas foram mantidas em vapor de nitrogênio por 2 minutos e armazenadas em nitrogênio líquido. Após a descongelação, os crioprotetores foram diluídos em duas etapas, usando $0,3 \mathrm{M}$ de sacarose e solução isotônica ou em três etapas usando $0,3 \mathrm{M}$ de sacarose $+10 \%$ de EG; $0,3 \mathrm{M}$ de sacarose e solução isotônica. Os embriões foram co-cultivados com células da granulosa, avaliando as taxas de re-expansão após 24 horas e de eclosão após 24, 48, 72 e 96 horas. Para os grupos congelados no vapor e diluição do crioprotetor em duas etapas, as taxas de eclosão foram de 1,94; 11,88 e 6,06\% para $\mathrm{EG}_{17}, \mathrm{EG}_{22}$ e EG $\mathrm{E}_{28}$, respectivamente. Já para os grupos com diluição do crioprotetor em três etapas, as taxas de eclosão foram de 4,67; 9,90 e 10,78\% para $E_{17}, E_{22}$ e $\mathrm{EG}_{28}$, respectivamente.

\section{Introdução}

A produção animal vem sendo fortemente incrementada pelo emprego do melhoramento e pelas biotécnicas reprodutivas como a inseminação artificial, a transferência de embriões, a fecundação in vitro, a clonagem e a transgenia animal.

A criopreservação de embriões é de fundamental importância para facilitar a difusão do material genético superior dos animais em larga escala. Além disso, favorece o armazenamento dos embriões por longos períodos com reduzida perda da capacidade de desenvolvimento ${ }^{1}$.

As taxas de prenhez com embriões produzidos in vitro e transferidos a fresco e de embriões produzidos in vivo e transferidos após a descongelação estão em torno de 60 a $70 \%$, enquanto que para embriões produzidos in vitro e criopreservados, estes valores são inconstantes e mais baixos ${ }^{2}$.

O sistema de cultivo pode afetar o desenvolvimento e a qualidade dos blastocistos e a criotolerância pode ser um bom indicador da qualidade dos embriões ${ }^{3,4}$. Os embriões bovinos produzidos in vitro são mais sensíveis às injúrias decorrentes dos efeitos tóxicos e osmóticos dos crioprotetores, assim como à formação de cristais de gelo ${ }^{5}$. Os métodos empregados para embriões produzidos in vivo não se mostraram tão satisfatórios para embriões produzidos in vitro ${ }^{6}$.

A viabilidade dos embriões pósdescongelação pode ser verificada por diferentes métodos, o mais comum é o cultivo por 24 ou 48 horas. Entretanto, a correlação entre a taxa de prenhez e a sobrevivência in vitro dos embriões é considerada baixa ${ }^{1}$.

Os fatores que vêm recebendo maior atenção são os crioprotetores, as receptoras de embriões, as velocidades de congelação, os processos de descongelação e os procedimentos de diluição dos crioprotetores ${ }^{7}$. 
Maior atenção tem sido dada ao processo de descongelação, pois a maior parte das fraturas de embriões ocorre neste momento ${ }^{8}$.

Portanto, o objetivo deste trabalho foi estudar a remoção do crioprotetor em duas ou três etapas em embriões bovinos produzidos in vitro após a congelação em vapor de Nitrogênio.

\section{Materiais e Métodos}

Foram utilizados ovários oriundos de matadouro. Os folículos foram aspirados e o líquido folicular mantido em tubo por 10 minutos. O sedimento foi examinado em placa de petri para localização e seleção dos oócitos. Os melhores oócitos foram lavados em meio de lavagem (TCM 199 Hepes) e colocados para maturar in vitro (MIV) em microgotas do meio de maturação (TCM 199 Bicarbonato, FSH, LH e Estradiol) por 24 horas, em estufa com 5\% $\mathrm{CO}_{2}$ em ar, $39^{\circ} \mathrm{C}$ e alta umidade.

O sêmen foi descongelado e centrifugado em gradiente de Percoll por 30 minutos a 700g (Labofuge 300 Heraeus). $\mathrm{O}$ sedimento foi ressuspendido e a concentração corrigida para $1 \times 10^{6}$ espermatozóides por $\mathrm{ml}$ do meio de fecundação. Os oócitos maturados foram lavados em meio de lavagem (TCM 199 Hepes) e em meio de fecundação acrescido de agentes capacitores e incubados em microgotas do meio de fecundação, onde foram acrescentados os espermatozóides. As placas de petri foram mantidas em estufa com $5 \%$ de $\mathrm{CO}_{2} \mathrm{em}$ ar, $39^{\circ} \mathrm{C}$ e alta umidade. $\mathrm{O}$ dia da fecundação é considerado como dia zero (D0).

Após 18 horas da fecundação, os prováveis zigotos foram cultivados (TCM 199 Bicarbonato) após remoção mecânica das células do cumulus. Após 48 horas de cultivo foram acrescidos $90 \mathrm{ml}$ do meio de cultivo (TCM 199 Bicarbonato) às microgotas (feeding). Os embriões foram avaliados a partir do sétimo dia após a fecundação. Alguns embriões foram deixados nas placas de petri para avaliação da taxa de eclosão.

Os blastocistos expandidos de qualidade excelente (grau 1) foram congelados em vapor de nitrogênio, sendo inicialmente equilibrados em solução de PBS com $10 \%$ de EG por 10 minutos e depois em soluções de PBS com $17 \%, 22 \%$ ou $28 \%$ de EG por 30 segundos, incluindo o tempo de envase.

Os embriões foram envasados em grupos de até 6 por palheta de $0,25 \mathrm{ml}$, preenchendo as colunas das extremidades (cerca de $4 \mathrm{~cm}$ ) com PBS; 0,3M de Sacarose e $0,2 \%$ de BSA, duas colunas com ar (com cerca de $1 \mathrm{~cm})$ para separar as colunas das extremidades da coluna central (cerca de $1 \mathrm{~cm}$ ) que continha a solução crioprotetora e os embriões dos grupos com remoção do crioprotetor em 2 etapas.

Já para os grupos com remoção do crioprotetor em 3 etapas, as colunas das extremidades das palhetas (cerca de $4 \mathrm{~cm}$ ) foram preenchidas com PBS; 10\% de EG; $0,3 \mathrm{M}$ de Sacarose e $0,2 \%$ de BSA.

As palhetas foram colocadas em vapor de Nitrogênio (cerca de $0,8 \mathrm{~cm}$ da coluna de Nitrogênio Líquido a aproximadamente $-170^{\circ} \mathrm{C}$ ) por 2 minutos e depois imersas e armazenadas em Nitrogênio Líquido.

Os embriões foram descongelados por 10 segundos no ar e 20 segundos no banho-maria a $25^{\circ} \mathrm{C}$. Para a remoção do crioprotetor em 2 etapas, os embriões foram colocados em $0,5 \mathrm{ml}$ da solução de PBS; $0,3 \mathrm{M}$ de Sacarose e $0,2 \%$ de BSA e em 0,5ml da solução de PBS e $0,2 \%$ de BSA, ambas por 3 minutos. Para a remoção do crioprotetor em 3 etapas, os embriões foram colocados em $0,5 \mathrm{ml}$ da solução de PBS; $10 \%$ EG; $0,3 \mathrm{M}$ de sacarose e $0,2 \%$ de BSA; em $0,5 \mathrm{ml}$ da solução de PBS; $0,3 \mathrm{M}$ de Sacarose e $0,2 \%$ de BSA e em $0,5 \mathrm{ml}$ da solução de PBS e $0,2 \%$ de BSA, todas por 3 minutos.

Todos os embriões foram cocultivados in vitro (TCM 199 Bicarbonato) com células da granulosa. Os embriões 
foram avaliados às 24 horas para verificar a taxa de re-expansão e às 96 horas para verificar a taxa de eclosão.

Os dados foram analisados pelo programa SAS System for Windows (SAS Institute Inc., Cary, NC, USA, 2000).

Para descrição dos resultados, foram empregadas as porcentagens e os valores absolutos.

O nível de significância para rejeitar H0 (hipótese de nulidade) foi de 5\%, isto é, para um nível de significância menor que 0,05 considerou-se que ocorreram diferenças estatísticas entre as variáveis classificatórias (tratamentos) para determinada variável resposta. Para verificar o efeito dos tratamentos (forma de congelação, tempo e concentração de Etileno glicol) sobre as variáveis resposta (taxa de re-expansão e taxa de eclosão) utilizou-se o teste de Kruskal Wallis quando o número de tratamentos foi maior do que 2 e o teste de Wilcoxon para comparação dois a dois.

\section{Resultados}

Como controle foram cultivados 716 blastocistos expandidos, os quais apresentaram taxa de eclosão de 70,95\%. Para os experimentos de congelação foram selecionados 613 blastocistos expandidos de qualidade excelente (grau1).

Os embriões equilibrados na solução de $10 \%$ de EG por 10 minutos e nas soluções de $17 \%$, $22 \%$ ou $28 \%$ de EG por
30 segundos, congelados no vapor de nitrogênio e com diluição do crioprotetor em 2 etapas apresentaram, respectivamente, taxas de re-expansão de 10,68; 14,85 e $12,12 \%$ às 24 horas e de eclosão de 1,94 ; 11,88 e $6,06 \%$ às 96 horas de co-cultivo (Tabela 1).

Já os embriões equilibrados na solução de $10 \%$ de EG por 10 minutos e nas soluções de $17 \%, 22 \%$ ou $28 \%$ de EG por 30 segundos, congelados no vapor de nitrogênio e com diluição do crioprotetor em 3 etapas apresentaram, respectivamente, taxas de re-expansão de 10,28; 17,82 e $14,70 \%$ às 24 horas e de eclosão de 4,67; 9,90 e $10,78 \%$ às 96 horas de co-cultivo (Tabela 1).

\section{Discussão}

Este estudo comparou diferentes concentrações de Etileno Glicol (EG) na congelação em vapor de nitrogênio e remoção do crioprotetor em duas ou três etapas em embriões bovinos produzidos in vitro.

Para verificar os efeitos do co-cultivo (controle), blastocistos expandidos produzidos in vitro foram co-cultivados por quatro dias, observando taxa de eclosão de $70,95 \%$ (Tabela 1). Esta taxa de eclosão foi superior aos grupos congelados em vapor de nitrogênioem razão do efeito deletério da criopreservação (Tabela 1). As concentrações e os tempos de equilíbrio no EG não foram suficientes para impedir os danos

Tabela 1- Taxas de eclosão dos grupos controle e congelados em vapor de Nitrogênio - São Paulo - 2003

\begin{tabular}{ccccc}
\hline & Grupo & & Eclosão \% (N) & $\mathrm{p}^{*}$ \\
Controle (FIV) & & $70,95(508 / 716)$ & \\
Vapor & $10 \mathrm{~min}$ & EG 17 & $01,94(02 / 103)$ & $<, 0001$ \\
& $+30 \mathrm{seg}$ & EG 22 & $11,88(12 / 101)$ & $<, 0001$ \\
+2 etapas & EG 28 & $06,06(06 / 99)$ & $<, 0001$ \\
& $10 \mathrm{~min}$ & EG 17 & $04,67(05 / 107)$ & $<, 0001$ \\
& +30 seg & EG 22 & $09,90(10 / 101)$ & $<, 0001$ \\
+3 etapas & EG 28 & $10,78(11 / 102)$ & $<, 0001$ \\
\hline
\end{tabular}

$\mathrm{p}^{*}: \mathrm{p}<0,05$ indica diferença estatística pelo teste de Wilcoxon

p* comparação das taxas de eclosão do grupo controle com os grupos congelados em vapor 
Tabela 2 - Efeito das etapas de diluição do crioprotetor sobre as taxas de re-expansão e de eclosão de embriões congelados em Vapor de nitrogênio após equilíbrio em 10\% de EG por 10 minutos e em 17\%, 22\% ou 28\% de EG por 30 segundos - São Paulo - 2003

\begin{tabular}{cccc}
\hline & 2 etapas & 3 etapas & $\mathrm{p}^{*}$ \\
\hline Re-expansão & $12,54(38 / 303)^{\mathrm{a}}$ & $14,19(44 / 310)^{\mathrm{a}}$ & 0,2744 \\
Eclosão & $6,60(20 / 303)^{\mathrm{a}}$ & $8,39(26 / 310)^{\mathrm{a}}$ & 0,2011 \\
\hline
\end{tabular}

Letras minúsculas diferentes na mesma linha indicam diferença estatística pelo teste de Wilcoxon $(p<0,05)$

Tabela 3-Efeito das concentrações deEG sobre as taxas de reexpansão e de eclosão de embriões congelados em Vapor de nitrogênio após equilíbrio em $10 \%$ de EG por 10 minutos e em $17 \%$, 22\% ou $28 \%$ de EG por 30 segundos, com diluição do crioprotetor em 2 ou 3 etapas - São Paulo- 2003

\begin{tabular}{cccc}
\hline & $17 \%$ de EC & $22 \%$ de EC & $28 \%$ de EC \\
\hline Re-expansão & $10,48(22 / 210)^{\mathrm{a}}$ & $16,34(33 / 202)^{\mathrm{a}}$ & $13,43(27 / 201)^{\mathrm{a}}$ \\
Eclosão & $3,33(7 / 210)^{\mathrm{a}}$ & $10,89(22 / 202)^{\mathrm{b}}$ & $8,46(17 / 201)^{\mathrm{b}}$ \\
\hline
\end{tabular}

Letras minúsculas diferentes na mesma linha indicam diferença estatística pelo teste de Wilcoxon $(p<0,05)$

Tabela 4-Efeito das etapas de diluição do crioprotetor e das concentrações de EG sobre as taxas de re-expansão de embriões congelados em Vapor de nitrogênio após equilíbrio em 10\% de EG por 10 minutos e em $17 \%$, 22\% ou 28\% de EG por 30 segundos - São Paulo - 2003

\begin{tabular}{lccc}
\hline & 2 etapas & 3 etapas & $\mathrm{p}^{*}$ \\
\hline $17 \%$ de EC & $10,68(11 / 103)^{\mathrm{aA}}$ & $10,28(11 / 107)^{\mathrm{aA}}$ & 0,4634 \\
$22 \%$ de EC & $14,85(15 / 101)^{\mathrm{aA}}$ & $17,82(18 / 101)^{\mathrm{aA}}$ & 0,2855 \\
$28 \%$ de EG & $12,12(12 / 99)^{\mathrm{aA}}$ & $14,70(15 / 102)^{\mathrm{aA}}$ & 0,2970 \\
\hline
\end{tabular}

Letras minúsculas diferentes na mesma linha indicam diferença estatística pelo teste de Wilcoxon $(p<0,05)$

Letras maiúsculas diferentes na mesma coluna indicam diferença estatística pelo teste de Wilcoxon $(p<0,05)$

Tabela 5 - Efeito das etapas de diluição do crioprotetor e das concentrações de EG e sobre as taxas de eclosão de embriões congelados em Vapor de nitrogênio após equilíbrio em $10 \%$ de EG por 10 minutos e em $17 \%, 22 \%$ ou $28 \%$ de EG por 30 segundos - São Paulo - 2003

\begin{tabular}{lccc}
\hline & 2 etapas & 3etapas & $\mathrm{p}^{*}$ \\
\hline $17 \%$ de EC & $1,94(2 / 103)^{\mathrm{aA}}$ & $4,67(5 / 107)^{\mathrm{aA}}$ & 0,1372 \\
$22 \%$ de EC & $11,88(12 / 101)^{\mathrm{aB}}$ & $9,90(10 / 101)^{\mathrm{AA}}$ & 0,3272 \\
$28 \%$ de EC & $6,06(6 / 99)^{\mathrm{aAB}}$ & $10,78(11 / 102)^{\mathrm{aA}}$ & 0,1162 \\
\hline
\end{tabular}

Letras minúsculas diferentes na mesma linha indicam diferença estatística pelo teste de Wilcoxon $(p<0,05)$

Letras maiúsculas diferentes na mesma coluna indicam diferença estatística pelo teste de Wilcoxon $(p<0,05)$

causados pela congelação.

A diluição do crioprotetor em 2 ou

3 etapas, não apresentou diferença significante entre as taxas de re-expansão e de eclosão de embriões congelados em vapor de nitrogênio após equilíbrio em 10\% de EG por 10 minutos e em $17 \%, 22 \%$ ou $28 \%$ de EG por 30 segundos (Tabela 2).

As diferentes concentrações de EG, na diluição do crioprotetor em 2 ou 3 etapas, não apresentaram diferenças significantes em relação as taxas de reexpansão dos embriões, porém houve diferença significante em relação as taxas de eclosão, sendo que as concentrações de $22 \%$ e 28\% apresentaram os resultados melhores, embora considerados baixos (Tabela 3).

As taxas de re-expansão não apresentaram diferença significante tanto entre as diluições do crioprotetor em 2 ou 3 etapas quanto entre as diferentes concentrações de EG (Tabela 4).

As taxas de eclosão apresentaram diferença significante entre as concentrações de EG na diluição do crioprotetor em 2 etapas, sendo que as melhores foram com 
$22 \%$ e $28 \%$, embora sejam considerados baixas. Já para diluição em 3 etapas não houve diferença entre as diferentes concentrações de EG (Tabela 5).

Dessa forma, observou-se que a diluição do crioprotetor em duas ou três etapas não influenciou as taxas de reexpansão e de eclosão, contrariando estudos de Kaidi et al. ${ }^{1}$ que recomendam maior número de etapas na diluição do crioprotetor para minimizar os danos osmóticos ao embrião, gerados pela movimentação da água através da membrana das células embrionárias.

Teoricamente, as altas concentrações de crioprotetor nas soluções de vitrificação exigiriam diluições em etapas, com grandes volumes de diluentes e alta concentração de sacarose para contrabaleancear o choque osmótico. Recentes pesquisas indicam que para alguns métodos de vitrificação pode ser feita a diluição na própria palheta, permitindo a transferência direta do embrião ${ }^{6}$.

A maior desvantagem da vitrificação é a necessidade de altas concentrações de crioprotetor, que é acompanhada pela toxicidade ao embrião. Muitos procedimentos vêm sendo propostos para minimizar esta toxicidade como a adição de macromoléculas e açúcares às soluções de vitrificação e a combinação de crioprotetores. Além disso, a taxa de resfriamento tem sido modificada constantemente para contornar a sensibilidade térmica de oócitos e embriões?.

A pré-congelação no vapor de nitrogênio antes da imersão em nitrogênio líquido reduz significativamente o rompimento das palhetas ${ }^{10}$. Por outro lado isto muda a velocidade de resfriamento durante a vitrificação, podendo ser prejudicial às células embrionárias ${ }^{11}$.

A vitrificação no vapor de nitrogênio é feita para prevenir fraturas que podem danificar o embrião ou a zona pelúcida. Estudo publicado por Vajta et al. ${ }^{12}$ mostrou que a fratura da zona pelúcida pode ocorrer por mudanças de pressão induzidas nas soluções pelo rápido encolhimento e ex-pansão de bolhas de ar durante as mudanças de temperatura. Portanto, a origem das fraturas, as condições ótimas de congelação e descongelação têm de ser encontradas para cada solução de vitrificação ${ }^{13}$.

Portanto, a remoção do crioprotetor em duas ou três etapas não mostrou dife-rença, sendo os resultados de criopreser-vação em vapor de nitrogênio insatisfatórios. Entretanto, por ser um procedimento pouco laborioso, merece novos estudos para viabilizar seu uso a campo.

\section{Cryopreservation and in vitro survival of bovine embryos.}

The aim of this study was to evaluate the dilution of cryoprotectant in 2 or steps of bovine in vitro-produced embryos after quick-freezing. A total of 1329 expanded blastocyst were kept in co-culture as control group or cryopreserved by 3 quick-freezing protocols. The embryos were exposed to $10 \% \mathrm{EG}$ for 10 minutes then to $17 \%, 22 \%$ or $28 \%$ for 30 seconds. After loading, the straws were held in nitrogen vapor for 2 minutes and then plunged and stored in liquid nitrogen. After warming, cryoprotectants were diluted in two steps using $0.3 \mathrm{M}$ sucrose and isotonic solution, or three steps using $0.3 \mathrm{M}$ sucrose $+10 \% \mathrm{EG}$ then $0.3 \mathrm{M}$ sucrose and isotonic solution. Embryos were co-cultured on a granulosa cell monolayer and evaluated after 24 hours for reexpansion and at 24, 48, 72 and 96 hours of co-culture for hatching rates. The in vitro survival rates of embryos cryopreserved by the quick-freezing method and two-step cryoprotectant dilution were 1.94; 11.88 and $6.06 \%$, for $\mathrm{EG}_{17}, \mathrm{EG}_{22}$ and $\mathrm{EG}_{28}$ groups, respectively. At the three step dilution, the in vitro survival rates were $4.67 ; 9.90$ and $10.78 \%$ for $\mathrm{EG}_{17}, \mathrm{EG}_{22}$ and $\mathrm{EG}_{28}$ groups, respectively.
Key-words:

Embryo.

Bovine.

Cryopreservation. 


\section{Referências}

$1 \mathrm{KAIDI}, \mathrm{S}$. Et al. Cellular alteration after dilution of cryoprotective solutions used for the vitrification of in vitro-produced bovine embryos. Theriogenology, v. 52, n. 3, p. 515-525, 1999.

2 SOMMERFELD, V.; NIEMANN, H. Cryopreservation of bovine in vitro produced embryos using ethylene glycol in controlled freezing or vitrification. Cryobiology, v. 38, n. 2, p. 95-105, 1999.

3 DOBRINSKY, J. R. Advancements in cryopreservation of domestic animal embryos. Theriogenology, v. 57, n. 1, p. 285-302, 2002.

4 RIZOS, D. et al. Effect of culture system on the yield and quality of bovine blastocysts as assessed by survival after vitrification. Theriogenology, v. 56, n. 1, p. 1-16, 2001.

5 VAJTA, G.; HYTTEL, P.; CALLESEN, H. Morphological changes of in vitro produced bovine blastocysts after vitrification, in straw direct rehydration, and culture. Molecular Reproduction and Development, v. 48, n. 1, p. 9-17, 1997.

6 LEIBO, S. P.; LOSKUTOFF, N. M. Cryobiology of in vitro-derived bovine embryos. Theriogenology, v. 39 n. 1, p. 81-94, 1993

7 SCHIEWE, M. C. The science and significance of embryo cryopreservation. Journal of Zoo and Wildlife Medicine, v. 22, n. 1, p. 6-22, 1991.

$8 \mathrm{KASAI}$, M.et al. Fracture damage of embryos and its prevention during vitrification and warming. Cryobiology, v. 33, n. 4, p. 459-464, 1996.

9 PUGH, P. A.; TERVIT, H. R.; NIEMANN, H. Effects of vitrification medium composition on the survival of bovine in vitro produced embryos, following in strawdilution, in vitro and in vivo following transfer. Animal Reproduction Science, v. 58, n. 1, p. 9-22, 2000.

10 RALL, W. F. Factors affecting the survival of mouse embryos cryopreserved by vitrification. Cryobiology, v. 24, n. 5 , p. 387-402, 1987.

11 DARVELID, U. Et al Survival rate and ultrastructure of vitrified bovine in vitro and in vivo development embryos. Acta Veterinaria Scandinavica, v. 35, n. 4, p. 417-426, 1994.

12 VAJTA, G. Successful vitrification of early stage bovine in vitro produced embryos with the open pulled straw (OPS) method. Cryo-letters, v. 18, p. 191-195, 1997a.

13 DONNAY, I. Et al. Vitrification of in vitro produced blastocysts: methodological studies and developmental capacity. Animal Reproduction Science, v. 52, n. 2, p. 93-104, 1998. 